\title{
Upcoming Therapeutic Modalities for the Treatment of Keloids: An Update
}

\author{
Keyal U1,2, Bhatta $\mathrm{AK}^{2}$
}

${ }^{1}$ Sumeru City Hospital, Pulchowk, Nepal; 'Let Me In Korean Aesthetic Skin Hospital, Baneshwor, Kathmandu, Nepal

\begin{abstract}
Introduction: Keloids are benign dermal tumors that generally form by local fibroblast proliferation and excessive collagen production following skin trauma. Several methods have been described for the treatment of keloid, often with suboptimal results and recurrences.

Objective: To update literature that provides information regarding upcoming therapeutic modalities for the treatment of keloids, including lasers, radiofrequency (RF), photodynamic therapy (PDT), and ultraviolet A1 (UVA1) irradiation.

Materials and Methods: A systematic review of the literature was performed for the original articles related to the treatment of keloids. The search terms 'keloids' and 'lasers' or 'radiofrequency' or 'PDT' or 'UVA1' was entered into a search of the National Library of Medicine's PubMed Database.

Result: The search returned a total of 188 sources, of which, 26 articles met our inclusion criteria.

Conclusion:Combination approach is superior than solo therapy in the treatment of keloid. However, it is highly desirable that new emerging therapies undergo large-scale studies with long-term follow-up before being recommended conclusively as alternative therapies for the treatment of keloid. Moreover, lack of randomized clinical trials (RCTs) needs to be taken into consideration urgently.
\end{abstract}

Key words: Collagen; Fibroblasts; Keloid; Photochemotherapy; Ultraviolet Therapy

\section{Introduction}

K eloids are benign dermal tumors that generally form bylocal fibroblast proliferation and excessive collagen production following skin trauma. ${ }^{1}$ Rarely, it can occur spontaneously in the absence of antecedent trauma. ${ }^{2}$ Keloids are unique to human andoccur more frequently in individuals with darker skin. ${ }^{3}$ The propensity of keloid formation in darker skin types is thought to be due in part by the larger multinucleated fibroblasts that have been described in this population. ${ }^{4}$ Keloids vary in size and shape, and do notregress spontaneously. They can be pedunculated or elevated with a flat surface, and may grow to sizes that can be disfiguring or crippling. Keloids range in consistency from soft and doughy torubbery hard and they may be tender, painful, pruritic, orcause a burning sensation. ${ }^{5}$ Histologically, they are characterized by exuberantdermal collagen formation with random

Address of Correspondence:

Dr. Anil Kumar Bhatta, PhD

Consultant Dermatologist

Let Me In Korean Aesthetic Skin Hospital,

Baneshwor, Kathmandu, Nepal

E-mail: bhattaanil@yahoo.com orientation and assembly of the individual collagen fibers. Uncontrolled fibroblast activity and excess collagen lead to overabundant extracellular matrix formation, and are the hallmark ofthese tumors. ${ }^{6}$ Although the exact pathogenesis of keloid is not elucidated, it has been known that keloid fibroblasts, when compared with normal fibroblasts, have lower rates of apoptosis. ${ }^{7}$ In addition, these cells over produces type I collagen and expresses higher levels of cytokines and growth factors, which influences

Submitted: $2^{\text {nd }}$ November 2018

Accepted: $1^{\text {st }}$ February 2019

Published: 31 $1^{\text {st }}$ March 2019

\section{How to cite this article}

Keyal U, Bhatta AK. Upcoming therapeutic modalities for the treatment of keloids: an update. Nepal Journal of Dermatology Venereology and Leprology. 2019;17(1):2-11. doi: http://dx.doi. org/10.3126/njdvl.v17i1. 23333

\section{(c) (i)}

Licensed under CC BY 4.0 International License which permits use, distribution and reproduction in any medium, provided the original work is properly cited. 
proliferation and collagen synthesis by fibroblasts. Another factor studied in the pathogenesis of keloid formation is the role of increased skin tension. This has postulated the skin injury-wound tension theory as the corner stone theory for keloid formation. ${ }^{1} \mathrm{~A}$ wide range of treatment modalities for keloid exists, which includes cryotherapy, surgical excision, intralesional injection with pharmacologic agents, mechanical pressure, and silicone gel dressings. None of these are $100 \%$ successful. Moreover, studies have shown lowered self-esteem and impaired quality of life in affected individuals. ${ }^{8}$ This calls for theinvestigation of new therapeutic interventions. Recently, attention has been drawn to the possible beneficial effects of newer therapies like lasers, radiofrequency, photodynamic therapy, and UVA1 irradiation. In the present review, we aim to update literature that provides information regarding upcoming therapeutic modalities for the treatment of keloids.

Many different lasers have been studied and utilized in the treatment of keloids including carbon dioxide (CO2) laser, 2940-nm erbium-doped: yttrium, aluminum and garnet (Er:YAG) laser, 1064-nm neodymiumdoped:yttrium, aluminum and garnet (Nd:YAG) laser, and 585-595 $\mathrm{nm}$ pulsed-dye lasers (PDL). CO2 and Er:YAG are ablative lasers, while $\mathrm{Nd}$ :YAG and PDL are non ablative lasers. CO2 laser and Er:YAG laser emit beams absorbed by water in skinresulting in local tissue destruction. ${ }^{9,10}$ Since the energy of the Er:YAG laser is due to its wavelength $(2,940 \mathrm{~nm})$ - largely absorbed by water, there is only very minor heat dissipation into the surrounding tissue; hence the term "cold" tissue ablation. ${ }^{11}$ The $\mathrm{CO} 2$ laser, on the other hand, with a wavelength of $10,600 \mathrm{~nm}$, generates moreheat in the surrounding tissue and also coagulates small blood vessels. ${ }^{11} \mathrm{Nd}$ : YAG laser is hypothesized to primarily treat keloids by damaging deepdermal blood vessels. ${ }^{12}$ Also, it may directly suppress fibroblastcollagen expression. ${ }^{12}$ Due to its wavelength $(1,064 \mathrm{~nm})$, however, the depth of penetration of theNd:YAG laser is much greater, a property shown to be useful in the treatment of Keloid scars. PDL is hypothesized to treat keloids by selective damage of blood vessels that supply the scar. ${ }^{13}$ With a wavelength of $595 \mathrm{~nm}$ or $585 \mathrm{~nm}$, oxyhemoglobin is the target chromophore of pulse dye laser (PDL). The near infrared diode laser has energy and wave length characteristics that specifically target the soft tissues. ${ }^{14}$ The $980 \mathrm{~nm}$ diode laser is selectively absorbed by haemoglobin and selectively destroys blood vessels, minimising injury to the surrounding healthy skin.The light energy released by the diode laser transformsinto heat, resulting in the vaporization of cells, a processreferred to as the photothermal effect. ${ }^{14}$

Radiofrequency tissue volume reduction (RFTVR) uses very low levels of radiofrequency energy tocreate controlled protein denaturation or necrosis insofttissue structures. ${ }^{15}$ Radiofrequency ablationcan be considered as minimally invasive treatment modality with no major disadvantages. ${ }^{16}$ Because of its mechanism of action, RFTVR appeared suitable for treatment of keloids.

Photodynamic therapy (PDT) is an established mode oftreatment for skin conditions such as Basel Cell Carcinoma, Actinic Keratosis and Bowens Disease.

This therapy is a non-invasive therapy that utilizes light treatments along with an application of a photosensitizing agent (PA). The PA is applied to the skin, causing the skin to become more susceptible, or receptive, to light. ${ }^{17}$ Once the incubation period of PA is complete, light of a specific wave length is directed onto the area to be treated, activating the protoporphyrin 9 (PpIX) and resulting in the formation ofcytotoxic reactive oxygen species. This causes cell apoptosis or necrosis, membrane and mitochondrialdamage and activates many signalling molecules, e.g. TNF- $\alpha$, interleukins 1 and $6 .{ }^{18}$ The potential mechanism of PDT in keloid may involve modulation of the growth factor and cytokine expression. ${ }^{18}$

Long-wave length UVA1 is different from other UV phototherapies because it offers deeper penetration as well as targeting fibrosis and other structures, i.e. fibroblasts, T-lymphocytes, Langerhans cells, mast cells, endothelial cells. ${ }^{19}$ UVA1 (340-400nm) acts deeper in the dermis andeven in the subcutaneous tissue. Moreover, around $20 \%$ of the radiation reaches vascular system, which, according tosome authors, provides grounds for a potential systemic action of this radiation range. ${ }^{19}$ UVA1 irradiation has been reportedto be effective for the treatment of morphea and systemicsclerosis through the induction of collagenase I [matrix metallo proteinase I (MMP-1)] production by fibroblasts and decreased synthesis of procollagen. The efficacy of UVA1for the treatment of keloid scarring may be partly the result of this action. ${ }^{20}$

\section{Method}

A systematic review of the literature was performed for the original articles related to the treatment of keloids. The search terms 'keloids' and 'lasers' or 'radiofrequency' or 'PDT' or 'UVA1' was entered into a search of the National Library of Medicine's PubMed 
Database. The search returned a total of 188 sources, of which, 26 articles met our inclusion criteria. Published clinical trials, case series, case reports, retrospective studies and letters reporting on keloid treatment using ablative lasers, non-ablativelasers, radiofrequency, PDT or UVA1 were included in this review. Unfortunately, randomized clinical trials on the relevant topic were not found. Only human studies and English language articles were selected. Articles about other skin conditionsor scar types other than keloids, including those that collectively mentioned hypertrophicscars and keloids, were excluded.In vitro studies were excluded. Figure 1 shows schematic diagram of search strategy listing the articles that met inclusion or exclusion criteria and Table 1 summarizes the characteristics of the 26 studies included in this review.

\section{Laser therapy}

Apfelberg DB et al reported the earliest study on laser treatment for keloids in 1984. ${ }^{21}$ Thirteen patients with well-established keloid scars of the trunk or earlobe were treated with either multiple-bore-hole argon technique alone or in combination with totalexcision with the $\mathrm{CO}_{2}$ laser. Only one patient with an earlobe keloid treated with argon laser alone showed total disappearance of keloid, all other patients had no improvement. In 1989, Apfelberg DB et al again treated seven patients with keloid on the trunk, nuchal region, back, and earlobe.22 Under local anesthesia, the keloids were excised sharplydown to the base by $\mathrm{CO} 2$ laser. Only one patient with earlobe keloid showed great improvement after only nine months' follow-up, all other patients had recurrence.
Ang CC et al reported case records of 16 patients with earlobe keloids. ${ }^{23}$ The patients received different treatment modalities including $\mathrm{CO} 2$ laser ablation, or cold steel surgery, or combined surgery and $\mathrm{CO} 2$ laser ablation, or $40 \mathrm{mg} / \mathrm{ml}$ of intralesional triamcinolone acetonide. Both the $\mathrm{CO} 2$ laser ablation and cold steel surgery were equally useful in reducing the size of the earlobe keloids, but were not effective in preventing regrowth of the keloids, even with adjunctive intralesional steroids. In contrast to the above studies, Morosolli AR et al observed a very good esthetic and functional result in a patient with anearlobe keloid treated with $\mathrm{CO} 2$ laser with a 0.8-mm focus, $7 \mathrm{~W}$, a power density of $2.5 \mathrm{~W} / \mathrm{cm} 2$, in a continuous mode. ${ }^{24}$ Similarly, Nicoletti $\mathrm{G}$ et al reported effectiveand well-tolerated treatment of keloids by $\mathrm{CO} 2$ laser. ${ }^{25}$ Fifty patients with moderate to severe keloids received regional treatments (deltoid, elbow, chin, and ear) with a high-energy pulsed $\mathrm{CO} 2$ laser. Diminished scarbulk with a reduction in scar height and textural improvement was noted in all the patients. Scrimali $L$ et al compared the effect of laser CO2 versus radiotherapy following surgical excision in the treatment of keloid and found that $\mathrm{CO} 2$ laser after surgical excision of keloids has great results with no recurrence and without the risk of carcinogenesis. ${ }^{26}$ Yang $Q$ et al reported a study with successful use of combination approach. ${ }^{27}$ One hundred and fifty onesites of keloids in 122 patients weretreated with combination methods of continuous-wave $\mathrm{CO} 2$ laser, ultra-pulse $\mathrm{CO} 2$ laserand 32P radiation. One hundred elevenof 151 evaluated sites scored "excellence"and 40 belonged to "effectiveness". These patients demonstrated local control and have remained free of local recurrence for more than two years.

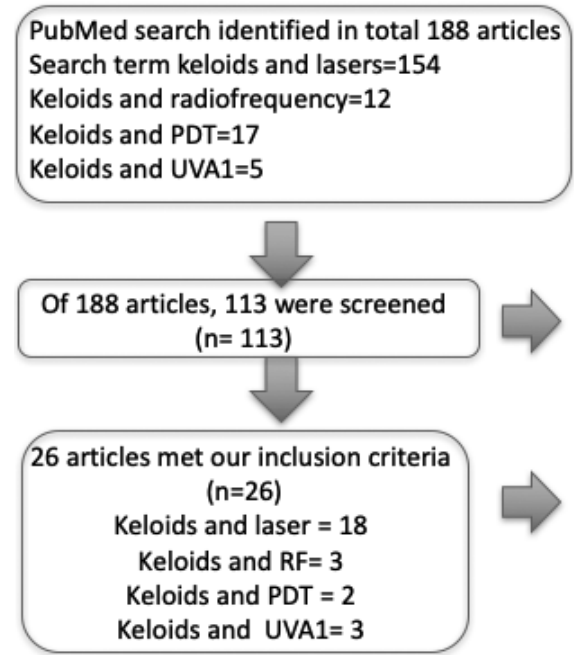

75 articles about skin conditions and scar types other than keloids were excluded

87 articles were excluded reviews $=52$ In vitro studies $\mathbf{1 6}$

Language other than English $=13$

Studies on animal models $=4$

Duplicates $=2$

Figure 1: Schematic diagram of search strategy listing the articles that met inclusion or exclusion criteria. 
Studies on laser therapy for keloids have shown more exciting results with PDL comparing to $\mathrm{CO} 2$ lasers. However, multiple treatments (>six) were required to yield better results than fewer treatments: $79 \%$ versus $50 \%$, respectively. Twelve months after final PDL treatments, keloid regression ( $\geq 50 \%$ ) had occurred in 26 out of 30 patients. ${ }^{28}$ Another study showed better result with PDL only after three sessions of treatment. ${ }^{29}$ Using the Vancouver scar scale (VSS), there was an average decrease of $20.85 \pm 12.33 \%$ after PDL treatment. Eke $U$ et al reported on the successful use of surgical shave-excision followed by single-pass PDL therapy for the treatment of keloid. ${ }^{30}$ Similarly, Cannarozzo $\mathrm{G}$ et al also reported a successful use of flash lamppumped PDL. ${ }^{31}$ This study recruited 59 patients who received four to six treatment sessions with a flash lamppumped PDL. A total of 29 patients out of 59 achieved excellent clearance, 15patients achieved good to moderate clearance, and 12 patients obtained slight improvement. Only three subjects had little or no removal of their lesion. Martin MS et al combined fractional $\mathrm{CO} 2$ laser with PDL as well as the injection of triamcinolone acetonide into the keloids refractory to solitary treatments of triamcinolone acetonide injection and other laser modalities. ${ }^{32}$ Treatments were carried out once per month for seven sessions. After five sessions, dramatic improvement in the lesions was seen.

Recently, studies on other types of lasers including $\mathrm{Nd}$ :YAG lasers, Er:YAG lasers, and 980nm diode laser with adjunctive intralesional or topical corticosteroids have shown good results in treating keloids. 14,33,34, The success rate in these studies varied from $50 \%$ to $75 \% .{ }^{14,34}$ More recently, Chen XE et al reported a successful use of long-pulsed Nd:YAG laser in combination with intralesional injection of diprospan and $0.5 \mathrm{ml} 5$-fluorouracil. ${ }^{35}$ In terms of invasiveness, two studies provided least invasive therapy. ${ }^{34-36}$ Cavalie $M$ et al treated 23 patients with 70 keloids with a 2940-nm ablative fractional erbium laser and topical betamethasone cream. ${ }^{34}$ The median percentage of improvement was $50 \%$ and a recurrence was observed for eight lesions at 18 months follow up. Similarly, Park JH et al treated keloids with an ablative fractional erbium-YAG laser and an intralesional injection or topical application of corticosteroid and concluded this treatment a promising modality for the treatment of keloids. ${ }^{36}$

\section{Radiofrequency}

Some small studies have proven the clinical safety and efficacy of RF in the treatment of keloids, especially in combination with adjuvant ILCS. It was in 2011, when Kai Fruth et al for the first time applied RFTVR in 14 patients with keloids of the auricle. ${ }^{15}$ In six patients, RFTVR was thesole treatment modality applied, and in seven patients IL steroid injection was also performed. Good cosmetic results were achieved in 10 of 14 patients. In 2013, Klockars T et al presented the second paper on this promising novel treatment option. ${ }^{37}$ They applied RF ablation in 11 patients (13 auricles) with single treatment session for all except one patient who was treated three times with three and 13 months interval. The effect of RF ablation was excellentin six auricles, good in five auricles and moderate in one auricle. In 2015, Weshay AH et alpresented the study on the combined effect of RF and IL steroids in the treatment of keloids. ${ }^{38}$ It was a pilot study on 18 patients who were subjected to three to four sessions of RF followed by IL steroid injection. A significant reduction of volume of all lesions in all patients was noted, with a mean volume reduction of 95.4\%.

\section{Photodynamic therapy}

In 2010, Nie Z et al reported the first study on PDT of keloids. ${ }^{18}$ It was a case report of the patient who had keloid under her chin for four years that had failed to respond to several other treatments,including surgical resection, but showed substantialimprovement with PDT. After five sessions of MAL-PDT over a period of 5 months, the patient's lesion had considerably reduced in size and become flattened and there was no recurrence at 1-year follow-up. Ud-Din S et alalso, in their clinical trial of 20 patients, proved the efficacy of PDT for keloids. ${ }^{39}$ The patientsunderwent three treatments of MAL-PDT at weekly intervals. All patients showed marked improvement except one patient who experienced recurrence of KD.All other patients had no recurrence at nine-month follow-up.

\section{UVA1 irradiation}

Asawanonda $P$ et al reported the first study on the successful use of UVA1 irradiation for the treatment of keloids in $1999 .{ }^{40}$ It was a case report where patient received $2860 \mathrm{~J} / \mathrm{cm} 2$ of UVA1 irradiation and responded well to the treatment. In contrary to this article reporting a successful treatment, HannukselaSvahn A et al found no effect of UVA1 irradiation on stable keloids. ${ }^{41}$ This was a study performed on threepatients with a several years history of a stable keloid secondary to tuberculinvaccine in the one patient and to acne in the other 2 patients. The patients received 1700, 1800 and $1500 \mathrm{~J} / \mathrm{cm} 2$ of UVA1 irradiation given strictly to the lesion alone. 


\begin{tabular}{|c|c|c|c|c|c|c|c|c|c|c|c|c|c|c|c|}
\hline 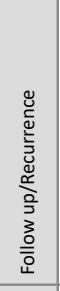 & 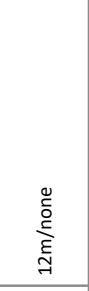 & 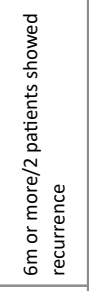 & 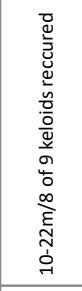 & 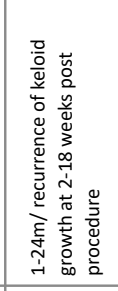 & 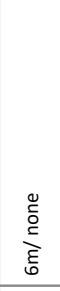 & 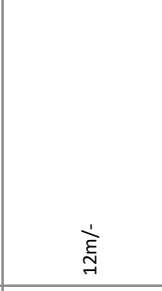 & 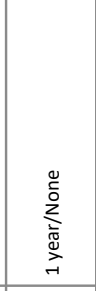 & $\begin{array}{l}\frac{0}{0} \\
\frac{0}{\pi} \\
\end{array}$ & 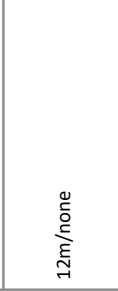 & & 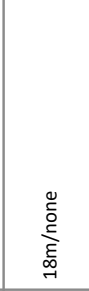 & हे & & & 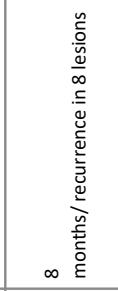 \\
\hline 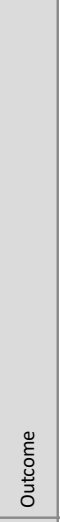 & 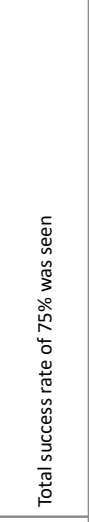 & 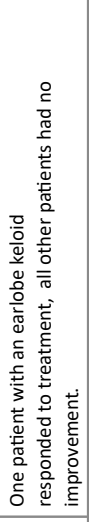 & 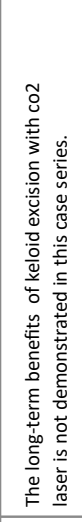 & 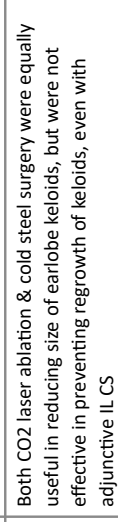 & 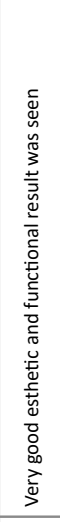 & 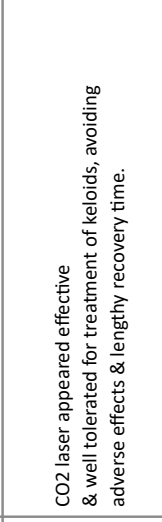 & 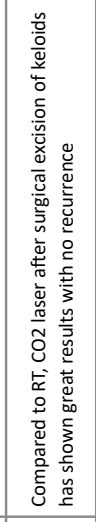 & 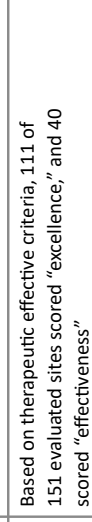 & 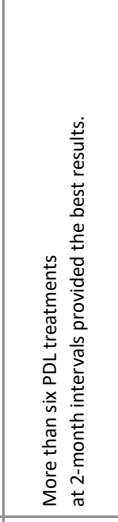 & 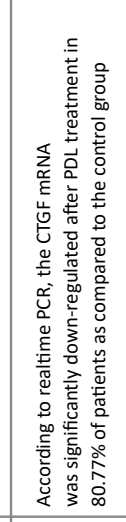 & 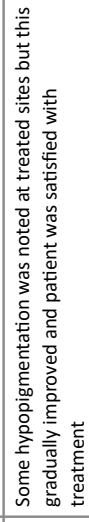 & 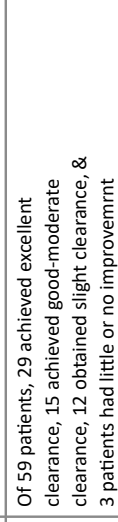 & 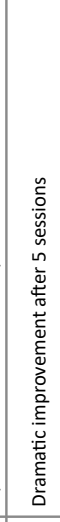 & 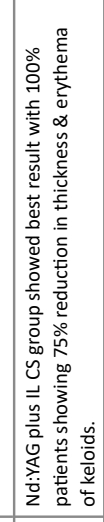 & 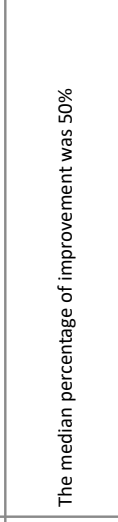 \\
\hline 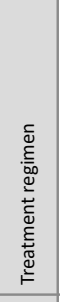 & 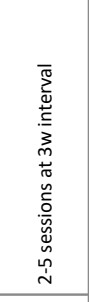 & 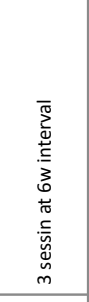 & & & & 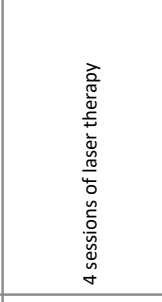 & 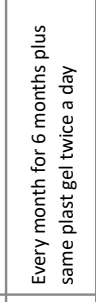 & & 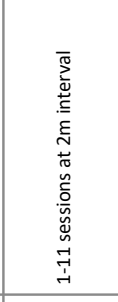 & 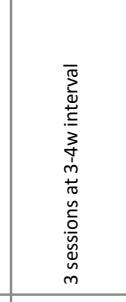 & & 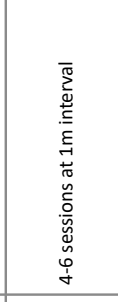 & 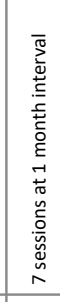 & 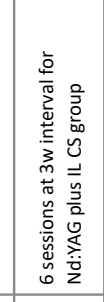 & 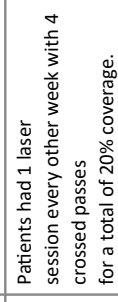 \\
\hline 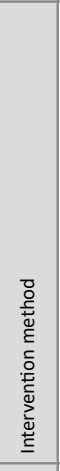 & 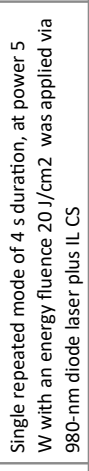 & 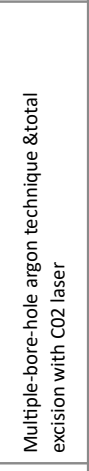 & 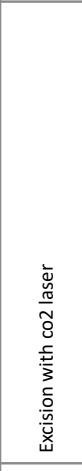 & 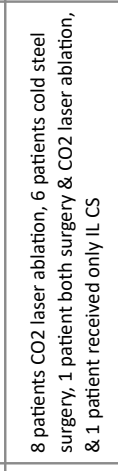 & 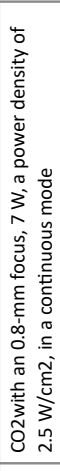 & 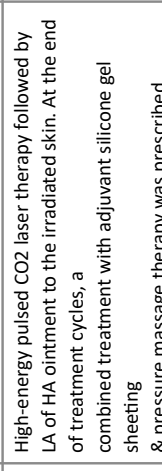 & 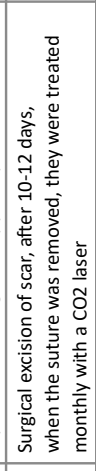 & 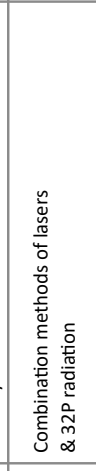 & 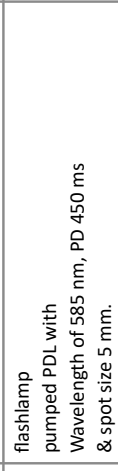 & 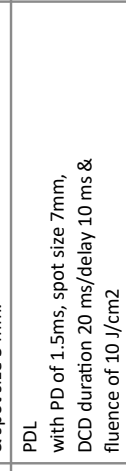 & 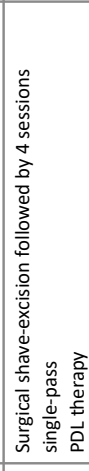 & 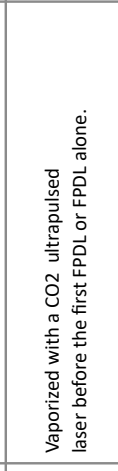 & 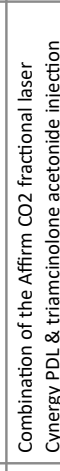 & 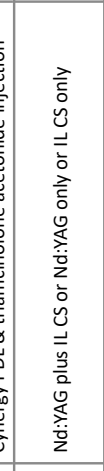 & 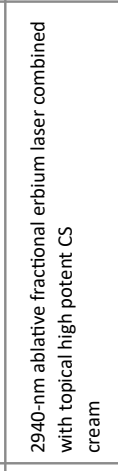 \\
\hline 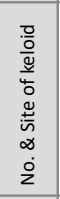 & 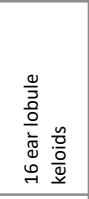 & 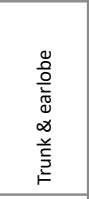 & 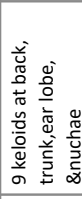 & 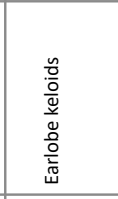 & 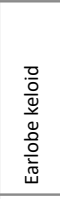 & 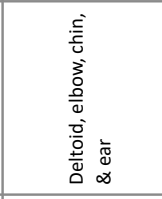 & 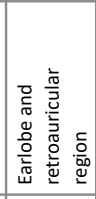 & 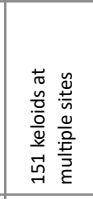 & 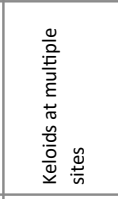 & 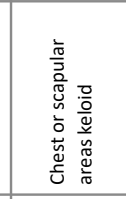 & 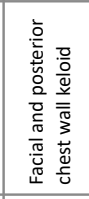 & 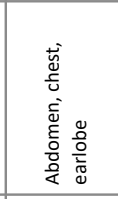 & 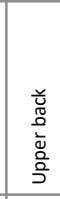 & & 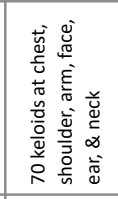 \\
\hline 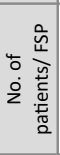 & 总 & $\frac{\dot{m}}{m}$ & $i$ & ذ্ল & $\dot{\vec{t}}$ & 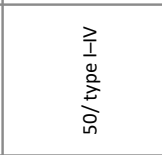 & $\dot{y}$ & 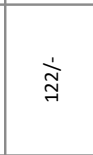 & के & 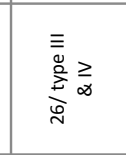 & 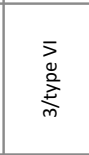 & 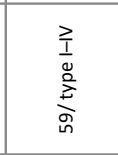 & $\frac{1}{\partial}$ & 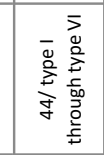 & 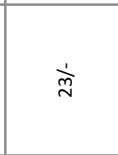 \\
\hline 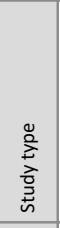 & 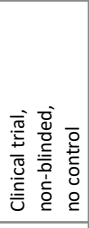 & 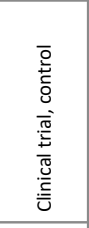 & 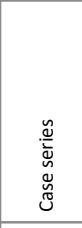 & 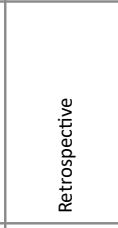 & 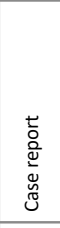 & 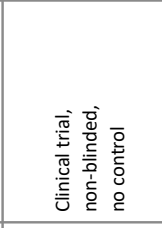 & & 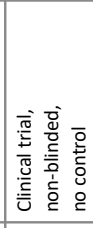 & 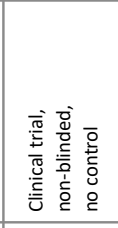 & 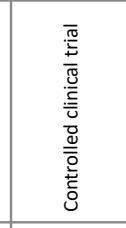 & 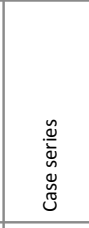 & 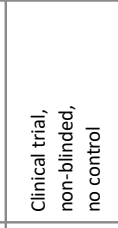 & 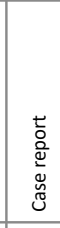 & 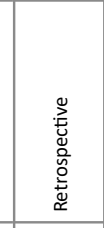 & 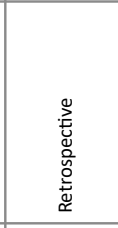 \\
\hline 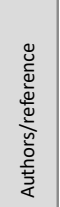 & 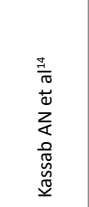 & 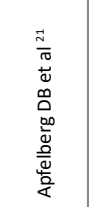 & 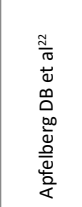 & 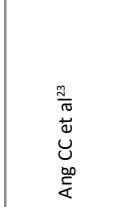 & 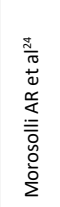 & 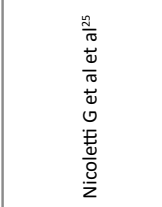 & 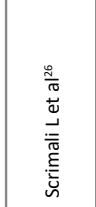 & 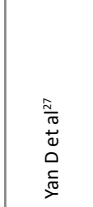 & 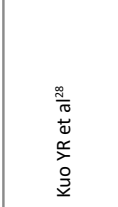 & $\begin{array}{l}\frac{8}{70} \\
\frac{0}{0} \\
0 \\
\frac{0}{00} \\
\frac{0}{x}\end{array}$ & 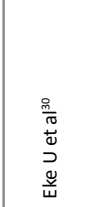 & 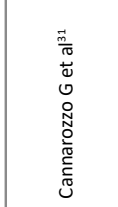 & 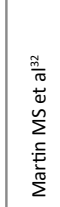 & 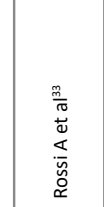 & 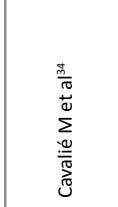 \\
\hline
\end{tabular}




\begin{tabular}{|c|c|c|c|c|c|c|c|c|c|c|c|c|}
\hline 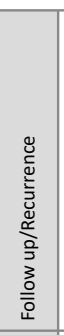 & 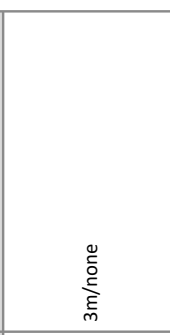 & 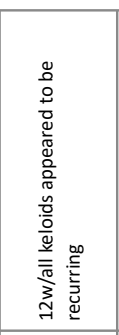 & 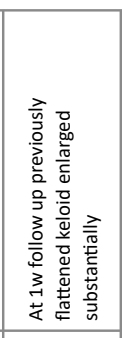 & 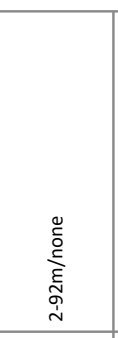 & & 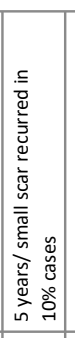 & 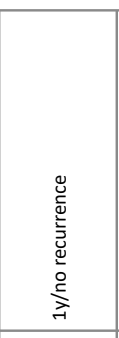 & 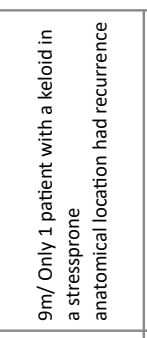 & & & & 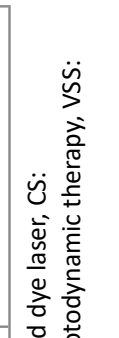 \\
\hline 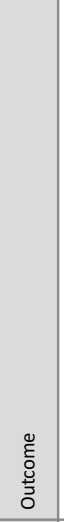 & 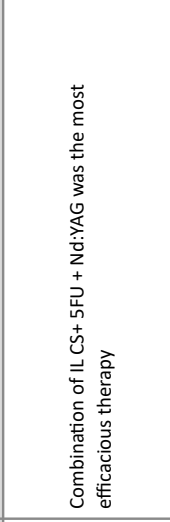 & 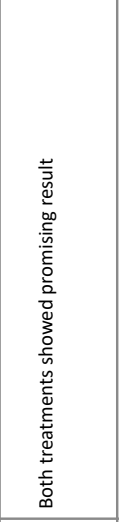 & 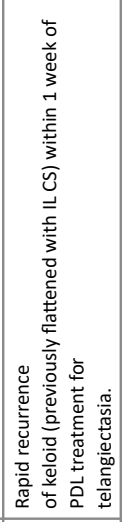 & 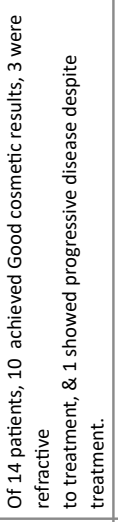 & 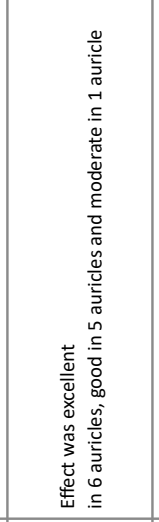 & 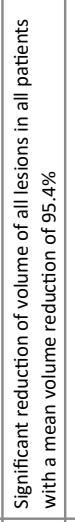 & 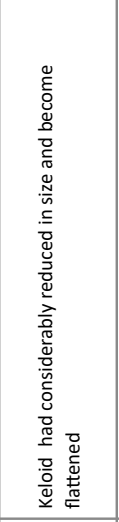 & 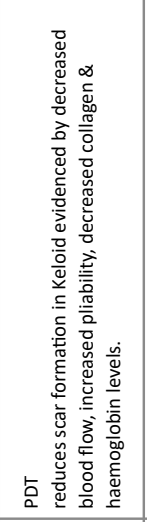 & 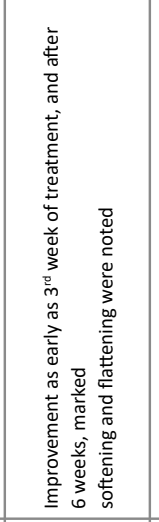 & 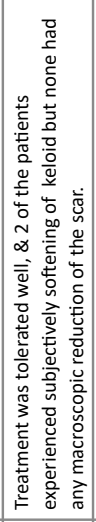 & 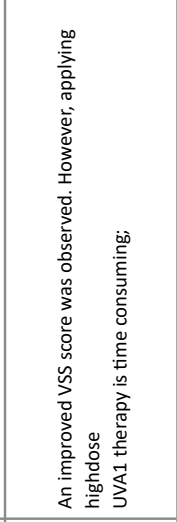 & 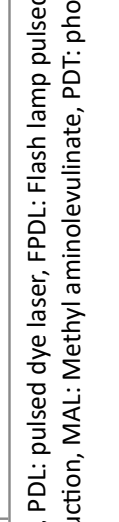 \\
\hline 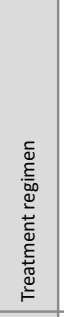 & 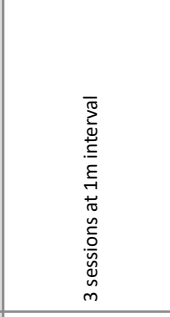 & 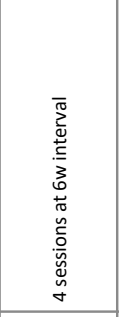 & 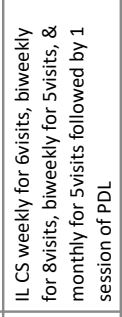 & 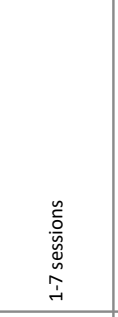 & 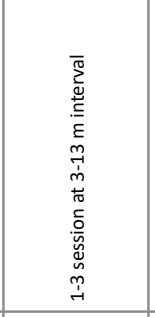 & 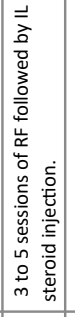 & 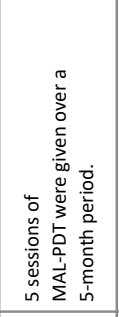 & 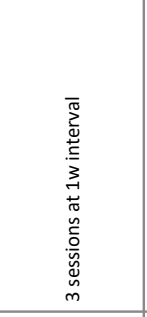 & 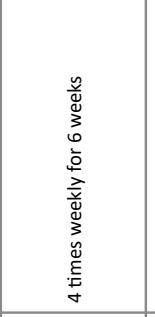 & 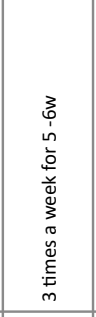 & 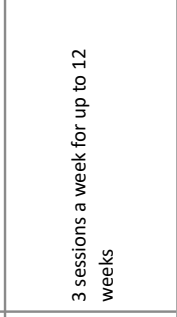 & 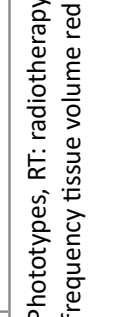 \\
\hline 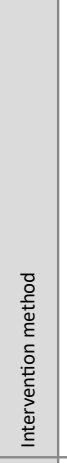 & 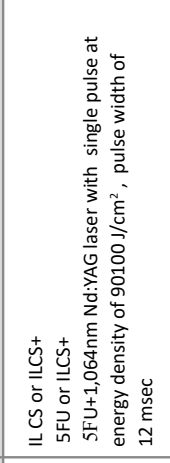 & 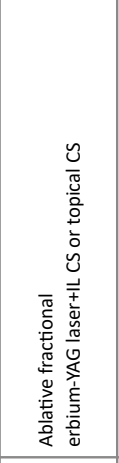 & 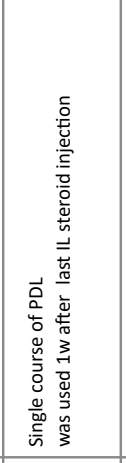 & 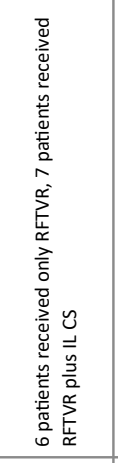 & 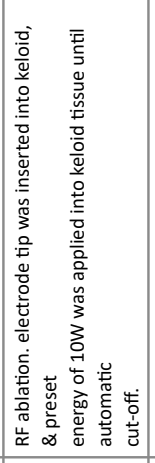 & 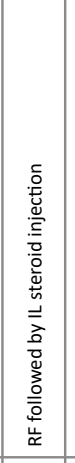 & 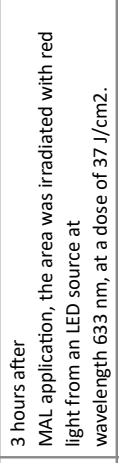 & 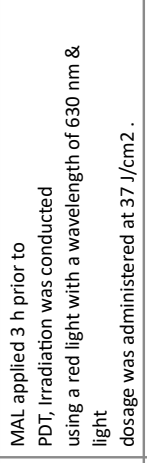 & 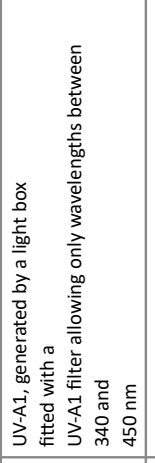 & 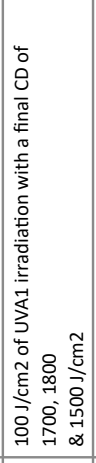 & 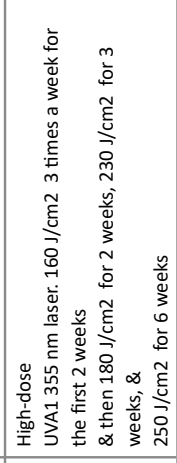 & 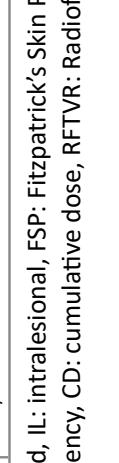 \\
\hline 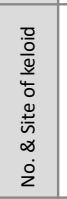 & 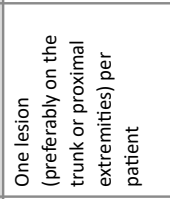 & 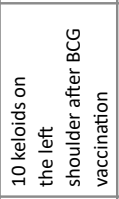 & 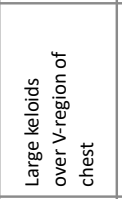 & 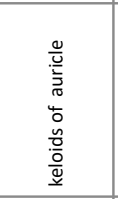 & 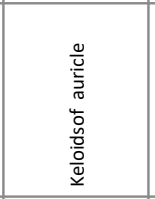 & 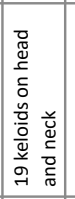 & 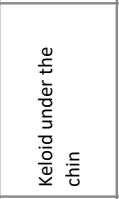 & 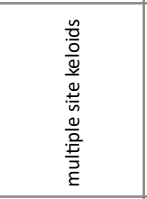 & 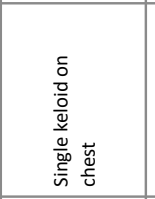 & 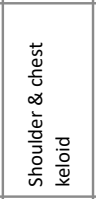 & 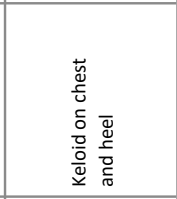 & 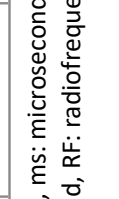 \\
\hline 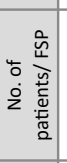 & बें & ১े & 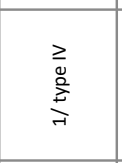 & ذे & $\vec{\partial}$ & 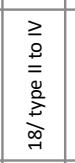 & $\dot{\partial}$ & ̀े & $\underset{\text { 崫 }}{\stackrel{0}{2}} \geq$ & $\frac{1}{m}$ & 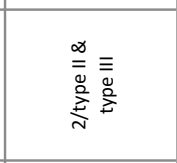 & $\frac{7}{5}$ \\
\hline 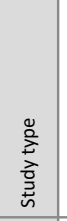 & 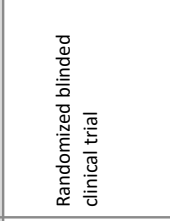 & 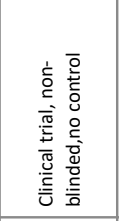 & 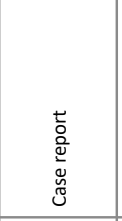 & 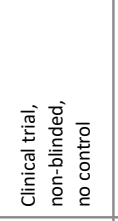 & 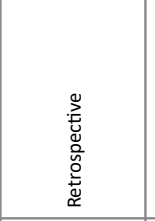 & 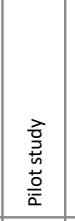 & 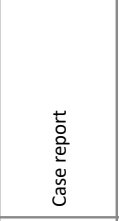 & 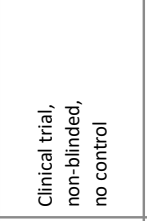 & 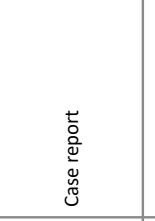 & 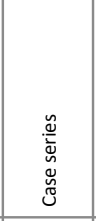 & 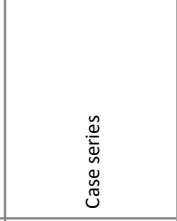 & 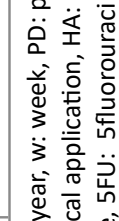 \\
\hline 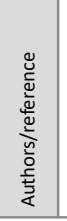 & 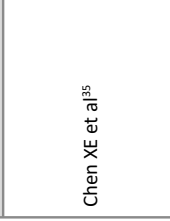 & 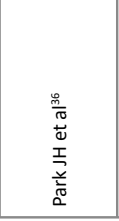 & 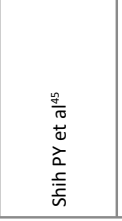 & 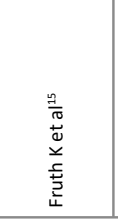 & 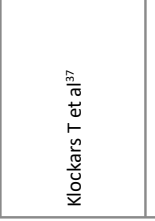 & 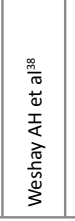 & $\begin{array}{l}\frac{\infty}{\pi} \\
\stackrel{N}{\tilde{N}} \\
\frac{\omega}{z} \\
\end{array}$ & 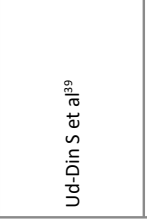 & 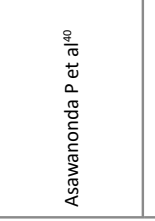 & 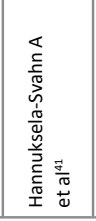 & 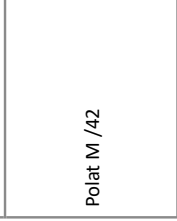 & 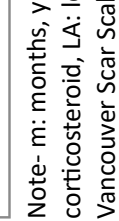 \\
\hline
\end{tabular}


The treatment was tolerated well, and two of the patients experienced subjectively softening of the keloid but none had any macroscopic reduction of the scar. The lack of response in the second experiment might be due to low dose of UVA1 comparing to the first study where high dose of UVA1 $(2860 \mathrm{~J} / \mathrm{cm} 2)$ was used. Recently in 2016, Polat M et al presented the results from two patients who underwent high dose UVA1 laser therapy. ${ }^{42}$ The treatment protocol applied in this study was: $160 \mathrm{~J} / \mathrm{cm} 2$ three times a week for the first two weeks then $180 \mathrm{~J} / \mathrm{cm} 2$ for two weeks, $230 \mathrm{~J} /$ $\mathrm{cm} 2$ for three weeks, and $250 \mathrm{~J} / \mathrm{cm} 2$ for six weeks for one patient. $140 \mathrm{~J} / \mathrm{cm} 2$ three times a week for the first three weeks, and then at $160 \mathrm{~J} / \mathrm{cm} 2$ for three weeks, $180 \mathrm{~J} / \mathrm{cm} 2$ for two weeks, $230 \mathrm{~J} / \mathrm{cm} 2$ for two weeks, and $250 \mathrm{~J} / \mathrm{cm} 2$ for two weeks for another patient. An improved VSS score was observed following treatment and complaint of itching and tenderness decreased significantly.

\section{Discussion}

In the past, the most recommended treatment strategy for keloid has been prophylaxis using silicone gel sheeting or paper tape starting on the second week after wounding, combined with other treatments, including massage, pressure therapy and intralesional corticotherapy, depending on each patient and scar's origin and type. ${ }^{43}$ None of these therapeutic options has been found completely effective and satisfactory. Moreover, patients with keloid scars suffer a severe impairment of quality of life, by causing physical, psychological and social sequelae. ${ }^{44}$ Recently, the promising results of some big and small studies has drawn attention to the possible beneficial effects of upcoming therapeutic modalities like lasers, radiofrequency, photodynamic therapy, and UVA1 irradiation. Among lasers, $\mathrm{CO}_{2}$ laser was seen to be effective for keloids as a solo therapy. ${ }^{24,25}$ It was also effective as an adjuvant therapy following surgical excision ${ }^{26}$. Results with other lasers like PDL, 980nm diode laser, Nd:YAG lasers, and Er:YAG laserswere also good in terms of patient satisfaction and recurrence. ${ }^{27-30,33,34}$ In these studies, combination approach showed better result than solo therapy. Laser treatments were mainly combined with surgical excision or ILCS. ${ }^{26,27,30,33}$ However, not all studies with laser showed exciting results. 2 studies with $\mathrm{CO} 2$ laser and 1 study with PDLshowed complete recurrence of keloids. ${ }^{22,23,45}$ These different outcome conclusionsare likely due to variations in keloid size, location and duration and also variations in treatment dosimetry and protocols.

Similarly, studies with RF showed better result when adjunctive ILCS was used. ${ }^{38}$ Three studies on RF reviewed here, all of which showed good result with no recurrence except one study where a small scar recurred in $10 \%$ of cases at five year follow up..$^{15,37,38}$ However, none of the other studies did this long duration follow up of five years. Both the studies on PDT reviewed here used MAL as a photosensitizing agent and irradiated the lesions using a red light with a wave length of $630 \mathrm{~nm}$ and light dosage at $37 \mathrm{~J} /$ $\mathrm{cm} 2 \cdot{ }^{18,39} \mathrm{All}$ the patients showed marked improvement and no recurrence except one patient with a keloid in a stress proneanatomical location that recurred. ${ }^{39}$ Unfortunately, studies on UVA1 failed to give exciting results. Three studies on UVA1 reviewed here reported the improvement in symptoms like itching and tenderness, but none reported the reduction of scar volume..$^{40-42}$

Unfortunately, most of the studies on keloids are noncontrolledarm,non-blinded, and non-randomized. The challenge of conducting double-blind RCTs for keloid treatment is the inherent difficulty in blinding patients and treatment operators. This may be the reason why cutaneous scar management has relied mainly on the experience of practitioners rather than on the results of large-scale randomized, controlled trials and evidence-based studies. ${ }^{43}$

\section{Conclusion}

In the case of keloids, combination approach is the best treatment modality. Successful therapeutic management need to address the conditions that initiate keloid formation, if not, keloid recurrence is likely and optimal management may not be achieved. In addition, it is highly desirable that many standard practices and new emerging therapies undergo largescale studies with long-term follow-up before being recommended conclusively as alternative therapies for the treatment of keloid. Moreover, RCTs are urgently needed.

Financial disclosure: None

Conflict of interest to disclosure: None declared. 


\section{References}

1. Louw L. The keloid phenomenon: progress toward a solution. Clin Anat. 2007; 20(1): 3-14. https://doi.org/10.1002/ca.20374

2. Shaffer JJ, Taylor SC, Cook-Bolden F. Keloidal scars: A reviewwith a critical look at therapeutic options. J Am Acad Dermatol. 2002; 46:S63-97. https:// doi.org/10.1067/mjd.2002.120788

3. Mrowietz U, Seifert O. Keloid scarring: new treatments ahead.Actas Dermosifiliogr. 2009; 100: 75-83. https://doi.org/10.1016/S00017310(09)73382-4.

4. Rawlings AV.Ethnic skin types: are there differences in skin structure and function? Int J Cosmet Sci. 2006; 28(2): 79-93. https://doi. org/10.1111/j.1467-2494.2006.00302.x

5. Kelly AP. Keloids.DermatolClin. 1988 Jul;6(3):413-24. https://doi.org/10.1016/S07338635(18)30653-3

6. Chiu LL, Sun $\mathrm{CH}$, Yeh AT, Torkian B, Karamzadeh A, Tromberg B et al. Photodynamic Therapy on Keloid Fibroblasts in Tissue-Engineered Keratinocyte-Fibroblast Co-Culture. Lasers SurgMed. 2005; 37:231-44. https://doi. org/10.1002/lsm.20213

7. Gauglitz GG, Korting HC, Pavicic T, Ruzicka $\mathrm{T}$, JeschkeMG. Hypertrophic scarring and keloids: pathomechanismsand current and emerging treatment strategies. Mol Med2011;17:113-25. https://doi.org/10.2119/ molmed.2009.00153

8. Barolet D, Boucher A.Prophylactic low-level light therapy for the treatment of hypertrophic scars and keloids: a case series. Lasers Surg Med. 2010; 42(6): 597-601. https://doi.org/10.1002/ Ism.20952

9. Alster TS. Cutaneous resurfacing with $\mathrm{CO} 2$ and erbium: YAG lasers: preoperative, intraoperative, and postoperative considerations. Plast ReconstrSurg 1999; 103: 619-32. https://doi. org/10.1097/00006534-199902000-00040.

10. Wagner JA, Paasch $U$, BodendorfMO,Simon JC, Grunewald S.Treatment of keloids and hypertrophic scars with the triple-mode Er:YAG laser: A pilot study. Med Laser Appl 2011; 26: 105. https://doi.org/10.1016/j.mla.2010.10.001.

11. Poetschke J, Gauglitz GG.Current options for the treatment of pathologicalscarring.J Dtsch Dermatol Ges. 2016; 14(5): 467-77. https://doi. org/10.1111/ddg.13027_g
12. Philipp CM, Scharschmidt D, Berlien HP. Laser treatment of scars andkeloids - How we do it. Med Laser Appl 2008; 23: 79-86. https://doi. org/10.1016/j.mla.2008.01.005

13. Garden JM, Tan OT, Kerschmann R, Boll J, Furumoto $H$, Anderson RR, Effect of dye laser pulse durationon selective cutaneous vascular injury. J Invest Dermatol 1986; 87:653-657. https://doi. org/10.1111/1523-1747.ep12456368.

14. Kassab AN, El Kharbotly A.Management of ear lobule keloids using 980-nm diode laser.Eur Arch Otorhinolaryngol. 2012; 269(2): 419-23. https:// doi.org/10.1007/s00405-011-1632-9

15. Fruth K, Gouveris H, Kuelkens C, Mann WJ.Radiofrequency tissue volume reduction for treatment of auricle keloids. Laryngoscope. 2011; 121(6): 1233-6. https://doi.org/10.1002/ lary. 21782

16. Bäck LJ, Liukko T, Sinkkonen ST, Ylikoski J, Mäkitie AA.Complication ratesofradiofrequencysurgeryin the upper airways: a single institutionexperience. Acta Otolaryngol. 2009; 129, 1469-73. https:// doi.org/10.3109/00016480802706719.

17. Keyal U, Bhatta AK, Wang XL.Photodynamic therapy for the treatment of different severity of acne: A systematic review.Photodiagnosis Photodyn Ther. 2016; 14:191-9. https://doi. org/10.1016/j.pdpdt.2016.04.005.

18. Nie Z, Bayat A, Behzad F, Rhodes LE. Positive response of a recurrent keloid scar to topical methyl aminolevulinate-photodynamic therapy. Photodermatol Photoimmunol Photomed. 2010; 26(6): 330-2. https://doi.org/10.1111/j.16000781.2010.00539.x

19. Osmola-Mańkowska A, Dańczak-Pazdrowska A,Olek-Hrab K, Silny W. Role of UVA1 phototherapy in treatmentof scleroderma and scleroderma-like disorders. Centr Eur J Immunol 2012; 37 (4): 391-8 https://doi.org/10.5114/ceji.2012.32731.

20. Petersen MJ, Hansen C, Craig S. Ultraviolet A irradiationstimulates collagenase production in cultured human fibroblasts.J Invest Dermatol 1992; 99:440-4. https://doi.org/10.1111/15231747.ep12616142

21. Apfelberg DB, Maser MR, Lash $H$, White $D$, Weston J.Preliminary results of argon and carbon dioxide laser treatment of keloid scars. Lasers Surg Med. 1984;4(3):283-90. https://doi.org/10.1002/ Ism.1900040309

22. Apfelberg DB, Maser MR, White DN, Lash H.Failure of carbon dioxide laser excision of 
keloids.Lasers Surg Med. 1989; 9(4): 382-8. https://doi.org/10.1002/Ism.1900090411

23. Ang CC, Tay YK, Kwok C.Retrospective analysis of earlobe keloids treated with the carbon dioxide laser ablation or cold steel debulking surgery.J Cosmet Laser Ther. 2013; 15(5): 271-3. https:// doi.org/10.3109/14764172.2013.769275

24. Morosolli AR, De Oliveira Moura Cardoso G, Murilo-Santos L, Niccoli-Filho W. Surgical treatment of earlobe keloid with $\mathrm{CO} 2$ laser radiation: Casereport and clinical standpoints. J Cosmet Laser Ther.2008; 10: 226-30. https://doi. org/10.1080/14764170802307957

25. Nicoletti G, De Francesco F, Mele CM, Cataldo C, Grella $\mathrm{R}$, Brongo $\mathrm{S}$ et al. Clinical and histologic effects from $\mathrm{CO} 2$ laser treatment of keloids. Lasers Med Sci. 2013; 28(3): 957-64. https://doi. org/10.1007/s10103-012-1178-0

26. Scrimali L, Lomeo G, Tamburino S, Catalani A, Perrotta R. Laser $\mathrm{CO} 2$ versus radiotherapy in treatment of keloid scars. J Cosmet Laser Ther. 2012; 14(2): 94-7. https://doi. org/10.3109/14764172.2012.671524

27. Yan D, Zhao B, Yang H, Zhu B, Wang J. A combination of nonoperative treatment modalities used for treatment of keloids. Dermatol Ther. 2014 ;27(1):48-51. https://doi. org/10.1111/dth.12044

28. Kuo YR, Jeng SF, Wang FS, Chen TH, Huang HC, Chang PR et al. Flashlamp pulsed dye laser (PDL) suppression of keloid proliferation through down-regulation of TGF-beta1 expression and extracellular matrix expression.Lasers Surg Med. 2004; 34(2): 104-8. https://doi.org/10.1002/ Ism.10206

29. Yang $Q$, Ma Y, Zhu R, Huang G, Guan M, Avram MM et al. The effect of flashlamp pulsed dye laser on the expression of connective tissue growth factor in keloids. Lasers Surg Med. 2012; 44(5): 377-83. https://doi.org/10.1002/lsm.22031

30. Eke U, Diaz C, Abdullah A.Keloid scars in type VI skin successfully treated with combined surgery and pulsed dye laser therapy. $\mathrm{Br} J$ Dermatol. 2013; 168(6): 1360-2. https://doi.org/10.1111/ bjd.12159

31. Cannarozzo G, Sannino M, Tamburi F, Morini C, Nisticò SP.Flash-lamp pulsed-dye laser treatment of keloids: results of an observational study. Photomed Laser Surg. 2015; 33(5): 274-7. https:// doi.org/10.1089/pho.2015.3895

32. Martin MS, Collawn SS. Combination treatment of $\mathrm{CO} 2$ fractional laser, pulsed dye laser, and triamcinolone acetonide injection for refractory keloid scars on the upper back. J Cosmet Laser Ther. 2013;15(3):166-70. https://doi. org/10.3109/14764172.2013.780448

33. Rossi A, Lu R, Frey MK, Kubota T, Smith LA, Perez $M$.The use of the 300 microsecond $1064 \mathrm{~nm}$ $\mathrm{Nd}$ :YAG laser in the treatment of keloids. J Drugs Dermatol. 2013; 12(11): 1256-62.

34. Cavalié $M$, Sillard L, Montaudié $H$, Bahadoran P, Lacour JP, Passeron T.Treatment of keloids with laser-assisted topical steroid delivery: a retrospective study of 23 cases.Dermatol Ther. 2015; 28(2): 74-8. https://doi.org/10.1111/ dth.12187

35. Chen XE, Liu J, Bin Jameel AA, Valeska M, Zhang $J A, X u Y$ et al. Combined effects of long-pulsed neodymium-yttrium-aluminum-garnet laser, diprospan and 5-fluorouracil in the treatment of keloid scars. Exp Ther Med. 2017;13(6):3607-12. https://doi.org/10.3892/etm.2017.4438

36. Park JH, Chun JY, Lee JH. Laser-assisted topical corticosteroid delivery for the treatment of keloids. Lasers Med Sci. 2017;32(3):601-8. https:// doi.org/10.1007/s10103-017-2154-5

37. Klockars T, Bäck LJ, Sinkkonen ST.Radiofrequency ablation for treatment of auricular keloids: our experience in eleven patients. Clin Otolaryngol. 2013; 38(5): 381-5. https://doi.org/10.1111/ coa.12169

38. Weshay AH, Abdel Hay RM, Sayed K, El Hawary MS, Nour-Edin F.Combination of radiofrequency and intralesional steroids in the treatment of keloids: a pilot study. Dermatol Surg. 2015; 41(6): 731-5. https://doi.org/10.1097/ DSS. 0000000000000360

39. Ud-Din S, Thomas G, Morris J, Bayat A.Photodynamic therapy: an innovative approach to the treatment of keloid disease evaluated using subjective and objective non-invasive tools. Arch Dermatol Res. 2013; 305(3): 205-14. https:// doi.org/10.1007/s00403-012-1295-4

40. Asawanonda P, Khoo LSW, Fitzpatrick TB, Taylor CR. UV-A1for keloid. Arch Dermatol 1999; 135: 348 - 9. https://doi.org/10.1001/ archderm.135.3.348

41. Hannuksela-Svahn A, Grandal OJ, Thorstensen T, Christensen OB.UVA1 for treatment of keloids. Acta Derm Venereol. 1999; 79(6): 490. https:// doi.org/10.1080/000155599750010076

42. Polat $M$, Kaya $H$, Şahin A.A New Approach in the Treatment of Keloids: UVA-1 Laser. Photomed Laser Surg. 2016; 34(3): 130-3. https://doi. org/10.1089/pho.2015.4046 
43. Mustoe TA, Cooter RD, Gold MH, Hobbs FD, Ramelet AA, Shakespeare PG et al.International Advisory Panel on Scar Management. International clinical recommendations on scar management. Plast Reconstr Surg 2002; 110(2): 560-71. https://doi.org/10.1097/00006534200208000-00031
44. Leventhal D, Furr m, Reiter D. Treatment of keloids and hypertrophic scars. Arch Facial Plast Surg 2006; 8:362-8. https://doi.org/10.1001/archfaci.8.6.362

45. Shih PY, Chen HH, Chen $\mathrm{CH}$, Hong HS, Yang $\mathrm{CH}$. Rapid recurrence of keloid after pulse dye laser treatment. Dermatol Surg. 2008;34(8):11247. https://doi.org/10.1111/j.1524- 